\title{
SPINAL ANESTHESIA; COMPARISON OF EPHEDRINE VERSUS PHENYLEPHRINE FOR PREVENTION OF SPINAL ANESTHESIA INDUCED HYPOTENSION IN PATIENTS.
}

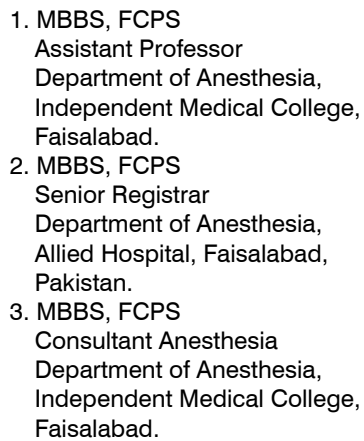

Article received on: 03/02/2017

Accepted for publication: 25/06/2017

Received after proof reading: 03/07/2017

\begin{abstract}
Shumyala Maqbool', Mohsin Riaz Askari², Beharam Khan ${ }^{3}$
ABSTRACT... Objectives: To compare ephedrine versus phenylephrine for prevention of spinal anesthesia induced hypotension in patients undergoing elective caesarean section. Design: It was a randomized controlled trial. Place and Duration of Study: This study was conducted at the Department of Anesthesia, Allied Hospital Faisalabad from July 2011 to December 2011. Material and Methods: 60 women having C-section under spinal anesthesia were included after written informed consent. These patients were randomly allocated into two treatment groups. Group-E received ephedrine $10 \mathrm{mg}$ intravenously and group-P received phenylephrine $100 \mu \mathrm{g}$ intravenously just after institution of spinal anesthesia. Outcome variable was frequency of spinal anesthesia induced hypotension which was noted and compared among the groups. A predesigned proforma was used to record patient's demographic details along with other study variables. Results: The mean age of the patients was $25.73 \pm 3.78$ years in Group-P and $26.07 \pm 4.32$ in Group $-E(p=0.37)$. There was significant difference in the mean heart rate $(85.50 \pm 2.64$ vs. $96.93 \pm 9.96 \mathrm{bpm} ; p=0.001)$ and mean systolic $(100.77 \pm 9.77$ vs. $94.00 \pm 9.28$ $\mathrm{mmHg} ; \mathrm{p}=0.007)$ and diastolic $(58.53 \pm 10.09$ vs. $53.03 \pm 8.78 ; p=0.028)$ blood pressure among the two groups (Group-P vs. Group-E) at 20 minutes after induction. The frequency of spinal anesthesia induced hypotension was significantly lower in patients receiving phenylephrine $(30.0 \%$ vs. $63.3 \% ; p=0.010)$ as compared to those receiving ephedrine. Similar significant difference was observed across various age and ASA-Class groups. Conclusion: The frequency of hypotension was significantly lower in patients receiving phenylephrine compared to ephedrine which advocate routine use of phenylephrine in such patients to minimize the risk of hypotension with associated morbidity.
\end{abstract}

Key words: $\quad$ Spinal Anesthesia, Hypotension, Ephedrine, Phenylephrine.

Article Citation: Maqbool S, Askari MR, Khan B. Spinal Anesthesia; Comparison of ephedrine versus phenylephrine for prevention of spinal anesthesia induced hypotension in patients. Professional Med J 2017;24(7):1049-1053.

DOI: $10.17957 / T P M J / 17.4016$

\section{INTRODUCTION}

Regional anesthesia is now used in more than $90 \%$ of caesarean sections presently due to its advantages for both the mother and the baby. ${ }^{1}$ Spinal anesthesia provides fast, profound and symmetrical sensory and motor block of high quality in patients undergoing caesarean delivery. ${ }^{2}$ Hypotension after spinal anesthesia for caesarean section has an incidence of up to $80 \%$ without prophylactic management. Preventive measures include fluid preload, lateral tilt and use of vasopressors. ${ }^{3}$ Hypotension following spinal anesthesia for caesarean section may result in maternal nausea, vomiting and decreased uteroplacental blood flow with possible fetal academia. ${ }^{4}$
The management of choice for this common problem is the use of intravenous vasopressors as required. ${ }^{5}$ However, there is disagreement about the choice of vasopressor and the ideal method of delivery. While choosing a suitable vasopressor in obstetric practice, various factors need to be considered. These include efficacy in preventing hypotension, maternal side effects, ease of use, direct and indirect fetal effects and finally the cost and availability. ${ }^{6}$

Ephedrine is an indirect-acting, non-specific adrenergic agonist. ${ }^{6}$ Although ephedrine has mixed alpha (a) and beta (B) adrenoceptor activity, it maintains arterial pressure mainly by increasing cardiac output through an increase of 
heart rate as a result of its predominant activity on B1-adrenoceptors. ${ }^{7}$ Phenylephrine is a noncatecholamine with predominantly direct a1agonist activity (high doses may stimulate a2 and B-receptors) the primary effect of phenylephrine is peripheral vasoconstriction with a concomitant rise in systemic vascular resistance and arterial blood pressure. ${ }^{8}$

Existing literature contained conflicting evidence regarding the frequency of hypotension after prophylactic use of ephedrine versus phenylephrine making the choice of agent in routine practice difficult. ${ }^{9-17}$ Also there was limited local evidence ${ }^{11,12}$ which necessitated the present study.

\section{MATERIAL AND METHODS}

This was a randomized controlled trial conducted at the Department of Anesthesia, Allied Hospital Faisalabad over 6 months from July 2011 to December 2011. Sample size of 60 cases (30 in each group) was calculated with $80 \%$ power of test and $95 \%$ confidence interval taking expected frequency of spinal anesthesia induced hypotension to be $30 \%$ in phenylephrine ${ }^{9}$ and $67.5 \%$ in ephedrine groups. ${ }^{10}$ Non-probability, consecutive sampling was done and 60 patients undergoing $\mathrm{C}$-section at operation theatres of Allied Hospital Faisalabad were included into this study after taking written informed consent. We only included patients with singleton pregnancy at term ( $\geq 37$ completed weeks of gestation) falling under American Society of Anesthesiologists (ASA) Class I and II. Patients with pregnancy induced hypertension, placenta accreta, placenta previa, diabetes mellitus, cardiovascular or pulmonary disease, coagulopathy, spinal cord abnormalities, previous spinal surgery or preexisting neurological deficit and those with allergy to local anesthetic drugs were excluded. These patients were randomly allocated into two treatment groups. Patients in Group-E received ephedrine 10mg intravenously while patients in Group-P received phenylephrine $100 \mu \mathrm{g}$ intravenously just after institution of spinal anesthesia. Standard monitoring was applied to all the patients including pulse oximetry, non-invasive blood pressure (NIBP) and ECG monitoring. Every patient was loaded with $500 \mathrm{ml}$ Lactated Ringers solution. One baseline reading of blood pressure and heart rate was taken before giving spinal anesthesia with $25 \mathrm{G}$ pencil point needle in sitting position with $15 \mathrm{mg}$ hyperbaric bupivacaine. All patients were immediately placed in supine position with 15 degree lateral tilt to prevent aortocaval compression. Hypotension (systolic blood pressure lower than $90 \mathrm{mmHg}$ ) was treated with bolus administration of vasoconstrictor (ephedrine or phenylephrine) at $50 \%$ of the initial dose and $200 \mathrm{ml}$ of Lactated Ringers solution intravenously. Heart rate, systolic blood pressure, and diastolic blood pressure were measured every two minutes for $1^{\text {st }} 2$ minutes and then every five minutes for the next 15 minutes. Outcome variable was drop of systolic blood pressure of the patient $\leq 90 \mathrm{mmHg}$ during the first 20 minutes which was labeled as hypotension and was recorded in a predesigned proforma along with demographic details of the patient. All the spinal injections and patients' observation were done by a single consultant who was blinded about the treatment group to eliminate bias.

\section{RESULTS}

Demographic details of the patients have been summarized in Table-I. There was significant difference in the mean heart rate $(85.50 \pm 2.64$ vs. $96.93 \pm 9.96$ bpm; $p=0.001)$ and mean systolic $(100.77 \pm 9.77$ vs. $94.00 \pm 9.28 \mathrm{mmHg} ; p=0.007)$ and diastolic $(58.53 \pm 10.09$ vs. $53.03 \pm 8.78$; $\mathrm{p}=0.028$ ) blood pressure among the two groups (Group-P vs. Group-E) at 20 minutes after induction. The frequency of spinal anesthesia induced hypotension was significantly lower in patients receiving phenylephrine $(30.0 \%$ vs. $63.3 \% ; p=0.010$ ) as compared to those receiving ephedrine as shown in Table-II Similar significant difference was observed across various age and ASA-Class groups.

\section{DISCUSSION}

Hypotension during spinal anesthesia in patients undergoing caesarean section is secondary to blockade of the sympathetic system and it can cause harm to both the mother and the baby. 


\begin{tabular}{|c|c|c|c|}
\hline Characteristic & $\begin{array}{l}\text { Phenylephrine } \\
\quad n=30\end{array}$ & $\begin{array}{l}\text { Ephedrine } \\
\quad n=30\end{array}$ & $P$ value \\
\hline Age (years) & $25.73 \pm 3.78$ & $26.07 \pm 4.32$ & 0.37 \\
\hline \multicolumn{4}{|l|}{ Age Groups } \\
\hline $20-25$ years & $17(56.7 \%)$ & $16(53.3 \%)$ & \multirow{3}{*}{0.58} \\
\hline $26-30$ years & $10(33.3 \%)$ & $09 \quad 30.0 \%)$ & \\
\hline $31-35$ years & $03(10.0 \%)$ & $05(16.7 \%)$ & \\
\hline \multicolumn{4}{|l|}{ ASA Class } \\
\hline Class-I & $22(73.3 \%)$ & $24(80.0 \%)$ & \multirow{2}{*}{0.39} \\
\hline Class-II & $08(26.7 \%)$ & $06(20.0 \%)$ & \\
\hline \multicolumn{4}{|c|}{$\begin{array}{l}\text { Table-I. Demographic features of study participants } \\
\text { Independent sample t-test and chi-square test, Observed difference was statistically insignificant }\end{array}$} \\
\hline Characteristic & $\begin{array}{l}\text { Phenylephrine } \\
n=30\end{array}$ & $\begin{array}{l}\text { Ephedrine } \\
n=30\end{array}$ & $P$ value \\
\hline Mean Heart Rate (bpm) & $85.50 \pm 2.64$ & $96.93 \pm 9.96$ & $0.001^{*}$ \\
\hline Mean Systolic BP (mmHg) & $100.77 \pm 9.77$ & $94.00 \pm 9.28$ & $0.007^{\star}$ \\
\hline Mean Diastolic BP (mmHg) & $58.53 \pm 10.09$ & $53.03 \pm 8.78$ & 0.028 \\
\hline Hypotension ( $\mathrm{n} \%)$ & $09(30.0 \%)$ & $19(63.3 \%)$ & $0.010^{*}$ \\
\hline
\end{tabular}

The harmful effects include but are not limited to decline in placental blood flow, disturbance of fetal oxygen delivery and subsequent fetal acidosis, and maternal symptoms of decreased cardiac output, such as vomiting and altered state of consciousness. ${ }^{18}$ In women undergoing C-section, the frequency of hypotension after spinal anesthesia can be as high as $80 \% .^{19}$ Traditionally, ephedrine has been preferred vasopressor in obstetric practice..$^{20}$ It was alleged that ephedrine causes an increase in maternal blood pressure, thus maintaining placental blood flow. ${ }^{21}$ However, successive studies demonstrated that it can sometimes precipitate fetal acidosis. A 2004 meta-analysis established that $\geq 14 \mathrm{mg}$ doses of ephedrine did not reduce the frequency of maternal hypotension, but it triggered reactive hypertension and a small reduction in umbilical cord blood $\mathrm{Ph} .{ }^{22}$ Phenylephrine is a shortacting and potent vasoconstrictor that increases both systolic and diastolic blood pressure. It counteracts the vasodilatation and reestablishes baseline blood pressure. Conventionally, its use was limited to a second line vasoconstrictor in obstetrics because of the fear of vasoconstriction in the uteroplacental circulation. It regained attention in 1988 when Ramanathan and Grant ${ }^{17}$ found that it did not produce fetal acidosis while preventing maternal hypotension. Numerous studies have confirmed these findings and almost all have reported higher umbilical artery (UA) $\mathrm{pH}$ values in neonates born to phenylephrine treated mothers. ${ }^{23}$ However, there were concerns regarding its efficacy to prevent spinal anesthesia induced hypotension where some studies claimed it to be even better where other reported it to be far less effective compared to conventional practice of ephedrine..$^{9-17}$

In the current study, the frequency of spinal anesthesia induced hypotension was significantly lower in patients receiving phenylephrine (30.0\% vs. 63.3\%; $p=0.010$ ) as compared to those receiving ephedrine. Siddiqui et al. (2015) in another local study observed similar significantly lower frequency of hypotension with phenylephrine ( $8 \%$ vs. $22 \% ; p=0.0009$ ) as compared to ephedrine in women undergoing C-section at Civil Hospital Karachi. ${ }^{11}$ Rehman et al. in 2011 also observed similar significant difference $(17.1 \%$ vs. $65.7 \%$; $p<0.001)$ in patients undergoing spinal anesthesia for C-section at Shifa International Hospital, Islamabad. ${ }^{12}$ Ngan et al. (2008) also observed similar frequency of hypotension with phenylephrine and ephedrine (4\% vs. $32 \%$; p<0.05). ${ }^{13}$ However, Magalhães 
et al. (2009) conducted a similar study on women undergoing C-section and observed significantly lower frequency of hypotension with ephedrine $(70 \%$ vs. $93 \%$; $p<0.05)$ as compared to phenylephrine and concluded that ephedrine was superior to phenylephrine. ${ }^{9}$ Nazir et al. (2012) however didn't observe any significant difference in the frequency of hypotension between phenylephrine $(70 \%$ vs. $66 \% ; p>0.05)$ and ephedrine in Indian such patients and concluded both the drugs to be equally effective. ${ }^{14}$ Alkaissi et al. in 2017 also didn't observe any significant difference in the frequency of hypotension between these two groups $(60.7 \%$ vs. $66.7 \%$; $p=0.646$ ) in Palestinian population. ${ }^{15}$ Similar insignificant difference was reported by Cooper et al. $(48 \%$ vs. $68 \%$; $p=0.13)$ in British population. ${ }^{16}$

The results of the present study are in line with those of existing research and thus advocate the routine use of phenylephrine to decrease the occurrence of hypotension in patients undergoing spinal anesthesia. A very strong limitation to the present study was that we didn't compare the side effects of these two drugs particularly the frequency of fetal acidosis which is a very important concern in obstetric anesthesia and should be evaluated in future research.

\section{CONCLUSION}

The frequency of spinal hypotension was significantly lower in patients receiving phenylephrine compared to ephedrine which advocate routine use of phenylephrine in such patients to minimize the risk of hypotension with associated morbidity.

Copyright@ 25 June, 2017.

\section{REFERENCES}

1. Algert CS, Bowen JR, Giles WB, Knoblanche GE, Lain SJ, Roberts CL. Regional block versus general anesthesia for caesarean section and neonatal outcomes: a population-based study. BMC Med 2009; 7:20. doi:10.1186/1741-7015-7-20.

2. Braga AD, Frias JA, Braga FS, Pereira RI, Titotto SM. Spinal anesthesia for elective ceasarean section: use of different doses of hyperbaric bupivacaine associated with morphine and clonidine. Acta Cirurgica Brasileira 2013; 28(1):26-32. doi: 10.1590/ S0102-86502013000100005.
3. Mitra JK, Roy J, Bhattacharyya P, Yunus M, Lyngdoh NM. Changing trends in the management of hypotension following spinal anesthesia in cesarean section. J Postgrad Med 2013; 59(2):121-6. doi: 10.4103/00223859.113840 .

4. Bittner E, Butterly A, Mirzakhani H, Jayadevappa A, MacDonald T, George E, et al. Severe postoperative hemodynamic events after spinal anesthesia a prospective observational study. J Anesthesiol Clin Res 2012; 1(1):14. doi: 10.7243/2049-9752-1-14.

5. Nag DS, Samaddar DP, Chatterjee A, Kumar H, Dembla A. Vasopressors in obstetric anesthesia: A current perspective. World Journal of Clinical Cases : WJCC 2015; 3(1):58-64. doi:10.12998/wjcc.v3.i1.58.

6. Heesen M, Stewart A, Fernando R. Vasopressors for the treatment of maternal hypotension following spinal anaesthesia for elective caesarean section: past, present and future. Anaesthesia 2015; 70(3):2527. doi: 10.1111/anae.13007.

7. Veeser M, Hofmann T, Roth R, Klöhr S, Rossaint R, Heesen M. Vasopressors for the management of hypotension after spinal anesthesia for elective caesarean section. Systematic review and cumulative meta-analysis. Acta Anaesthesiol Scand 2012; 56(7):810-6. doi: 10.1111/j.1399-6576.2011.02646.x.

8. Butwick AJ, Columb MO, Carvalho B. Preventing spinal hypotension during Caesarean delivery: what is the latest? $\mathrm{Br} \mathrm{J}$ Anaesth 2015; 114(2):183-6. doi: 10.1093/ bja/aeu267.

9. Magalhaes E, Goveia CS, de Araujo Ladeira LC, Nascimento BG, Kluthcouski SM. Ephedrine versus phenylephrine: prevention of hypotension during spinal block for cesarean section and effects on the fetus. Rev Bras Anestesiol 2009; 59:11-20.

10. das Neves JF, Monteiro GA, de Almeida JR, Sant'Anna RS, Bonin HB, Macedo CF. Phenylephrine for blood pressure control in elective cesarean section: therapeutic versus prophylactic doses. Rev Bras Anestesiol 2010; 60:391-8. doi: 10.1016/S00347094(10)70048-9.

11. Siddiqui AS, Salim B, Siddiqui SZ. Comparison of phenylephrine and ephedrine for treating hypotension after spinal anesthesia for cesarean section: A Randomized double-blind clinical trial. Anaesth Pain Intensive Care 2015; 19(1):44-9.

12. Rehman A, Baig H, Rajput MZ, Zeb $H$. Comparison of prophylactic ephedrine against prn ephedrine during spinal anesthesia for caesarian sections. Anaesth Pain Intensive Care 2011; 15(1):21-4. 
13. Ngan Kee WD, Lee A, Khaw KS, Ng FF, Karmakar MK, Gin T. A randomized double-blinded comparison of phenylephrine and ephedrine infusion combinations to maintain blood pressure during spinal anesthesia for cesarean delivery: the effects on fetal acid-base status and hemodynamic control. Anesth Analg 2008; 107(4):1295-302. doi: 10.1213/ane.0b013e31818065bc.

14. Nazir I, Bhat MA, Qazi S, Buchh VN, Gurcoo SA. Comparison between phenylephrine and ephedrine in preventing hypotension during spinal anesthesia for cesarean section. Journal of Obstet Anaesth Critical Care 2012; 2(2):92-7.

15. Alkaissi A, Ussbah Q, Al-Bargouthi A. Prophylacic ephedrine versus phenylephrine for maternal hypotension in women undergoing spinal anesthesia for caesarean section. A Randomized Double Blind Clinical Trial. J Biomedical Sci 2017; 6:1-10.

16. Cooper DW, Carpenter M, Mowbray P, Desira WR, Ryall DM, Kokri MS. Fetal and maternal effects of phenylephrine and ephedrine during spinal anesthesia for cesarean delivery. Anesthesiology 2002; 97(6):1582-90.

17. Simin A, Zahra F, Pouya HM, Reza T. Comparison the effect of ephedrine and phenylephrine in treatment of hypotension after spinal anesthesia during cesarean section. Open J Obstet Gynecol 2012;2(03):192-6.
18. Rout CC, Rocke DA. Prevention of hypotension following spinal anesthesia for cesarean section. Int Anesthesiol Clin 1994; 32:117-35.

19. Hall PA, Bennett A, Wilkes MP. Spinal anaesthesia for Caesarean section: comparison of infusions of phenylephrine and ephedrine. $\mathrm{Br} J$ Anaesth, 1994; 73:471-4.

20. Burns SM, Cowan CM, Wilkes RG. Prevention and management of hypotension during spinal anaesthesia for elective Caesarean section: a survey of practice. Anaesthesia 2001; 56:794-8.

21. Ralston DH, Shnider SM, DeLorimier AA. Effects of equipotent ephedrine, metaraminol, mephentermine, and methoxamine on uterine blood flow in the pregnant ewe. Anesthesiology 1974; 40:354-70.

22. Lee A, Ngan Kee WD, Gin T. A dose-response metaanalysis of prophylactic intravenous ephedrine for the prevention of hypotension during spinal anesthesia for elective cesarean delivery. Anesth Analg 2004; 98:483-90.

23. LaPorta RF, Arthur GR, Datta S. Phenylephrine in treating maternal hypotension due to spinal anaesthesia for caesarean delivery: effects on neonatal catecholamine concentrations, acid base status and Apgar scores. Acta Anaesthesiol Scand 1995; 39:901-5.

\begin{tabular}{|c|c|l|l|}
\hline \multicolumn{3}{|c}{ AUTHORSHIP AND CONTRIBUTION DECLARATION } \\
\hline Sr. \# & \multicolumn{1}{|c|}{ Author-s Full Name } & \multicolumn{1}{|c|}{ Contribution to the paper } & Author=s Signature \\
\hline 1 & Shumyala Maqbool & $\begin{array}{l}\text { Data collection, Article } \\
\text { writing and result } \\
\text { preparation } \\
\text { Data collection, References } \\
\text { writing, Statistical analysis } \\
\text { and technical review } \\
\text { Result interpretation, } \\
\text { Statistical evaluation, } \\
\text { Technical review }\end{array}$ \\
\hline 3 & Dr. Beharam Khan & Mohsin Riaz Askari & \\
\hline
\end{tabular}

